\title{
Photodegradation of atrazine and ametryn with visible light using water soluble porphyrins as sensitizers
}

\author{
Susana L. H. Rebelo • A. Melo • R. Coimbra • \\ M. Emília Azenha • Mariette M. Pereira • \\ Hugh D. Burrows • Mohamed Sarakha
}

Received: 27 March 2006 / Accepted: 16 June 2006 / Published online: 10 November 2006

(C) Springer-Verlag 2006

\begin{abstract}
The photodegradation of the herbicides atrazine and ametryn with visible light in aerated neutral aqueous solutions and 5, 10, 15, 20-tetrakis (2,6-dichloro3-sulfophenyl) porphyrin or 5, 10, 15, 20-tetrakis (4sulfophenyl) porphyrin as sensitizers are reported for the first time. Our findings show that the degradation percentage reached $30 \%$ for atrazine and $63 \%$ for ametryn. The final photoproducts were characterized as dealkylated $s$-triazines. Photolysis of the pesticides in the presence of a singlet oxygen quencher showed only a minor contribution of this type of mechanism, while a bimolecular quenching reaction between the triplet state of the sensitizer and the pesticides is excluded by flash photolysis studies. It is proposed that the mechanism may involve the formation of a superoxide radical anion from the triplet state of the sensitizer and molecular oxygen, followed by a radical decomposition pathway.
\end{abstract}

Keywords Porphyrins · Atrazine - Ametryn · Photodegradation · Visible light · Oxygen

Selected article from 1st International Meeting on Photochemistry, Photocatalysis and Environmental Applications, Agadir, 2006, organised by Prof. Dr. Ait Ichou, University Ibn Zohr, Agadir, Morocco

S. L. H. Rebelo · A. Melo · R. Coimbra · M. E. Azenha $(\bowtie)$.

M. M. Pereira · H. D. Burrows

Departamento de Química, Universidade de Coimbra,

3004-535 Coimbra, Portugal

e-mail: meazenha@ci.uc.pt

Tel.: + 351239854465

Fax: +351239827703

M. Sarakha

Université Blaise-Pascal,

Clermont Ferrand, 63177 Aubière Cedex, France

\section{Introduction}

The quantity of pesticides and their metabolites present in surface and underground waters have been increased dramatically in the last decades. The inherent negative consequences for ecosystems and human health are pressing the efforts for the development of new technologies for water treatment, which are more efficient and environmentally clean. Photooxidation processes have major potential in this area (Legrini et al. 1993; Burrows et al. 2002; Oller et al. 2005; Lichtfouse et al. 2005). In particular, the photo-assisted degradation of organic pollutants in water in the presence of solar light, oxygen and a sensitizer is considered to be a very promising and low-cost methodology (Gryglik et al. 2004; Xiong et al. 2005).

Porphyrins and phthalocyanines have relatively high molar absorption coefficients in the visible region and high quantum yields for the formation of the corresponding photoexcited triplet states. This, together with their long-lived triplet state, makes them very strong potential candidates for efficient harvesting of sunlight for use as good sensitizers (Tai et al. 2005). The excited triplet state of the sensitizers can promote the activation of the pollutant molecule by electron or atom transfer (type I mechanism), by energy transfer to molecular oxygen, forming the highly reactive singlet oxygen species $\left({ }^{1} \mathrm{O}_{2}\right)$, which can then promote the oxidation of pollutants (type II mechanism) or by superoxide radical (Foote 1991; De Rosa et al. 2002; Burrows et al. 2002).

Atrazine (1) and ametryn (2) (Fig. 1) are extensively used herbicides, with high persistence in the environment. Atrazine is still one of the most widely used pesticides worldwide. It degrades slowly in waters, with negligible breakdown in neutral or slightly alkaline waters $\left(t^{1 / 2} \geq 2\right.$ years). At pH 5 and temperature $20{ }^{\circ} \mathrm{C}$, the half-life is about 12 


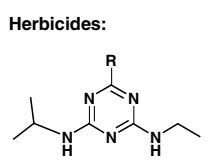

(1) $\mathrm{R}=\mathrm{Cl}$ Atrazine

(2) $\mathrm{R}=\mathrm{SCH} 3$ Ametryn
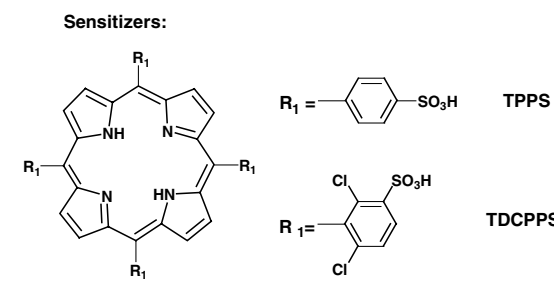

TDCPPS

Fig. 1 Herbicides and porphyrins used in photodegradation studies

weeks. This herbicide has relatively low adsorption in soil and easily migrates, leaching to water.

Photodegradation of atrazine or ametryn by $\mathrm{O}_{2}$ in the presence of sunlight or simulated sunlight has been reported using different sensitizers, such as methylene blue, rose bengal, flavin nucleotide, phthalocyanines and a naturally occurring hemin (Rejto et al. 1983; Héquet et al. 2000). However, as far as we know, porphyrins have not been applied as sensitizers with these compounds. For practical purposes, there is an urgent need for more efficient sensitizers, in addition to more mechanistic information (Azenha et al. 2003).

Recently, we have shown that 5, 10, 15, 20-tetrakis (2,6dichloro-3-sulfophenyl) porphyrin (TDCPPS) and some of its metal complexes are efficient sensitizers for the degradation of phenols and chlorophenols in water (Monteiro et al. 2005; Silva et al. 2004). In the present work, we extend these studies to the photodegradation of atrazine and ametryn using the water soluble porphyrins TPPS and TDCPPS (Fig. 1) as sensitizers. To obtain mechanistic information, photodegradation has also been performed in the presence of a singlet oxygen quencher, as well as flash photolysis studies with different concentrations of pesticides.

For practical applications, the recovery of the sensitizer is important, and with the systems studied this can be achieved by filtration over clays or other species.

\section{Experimental}

Atrazine (1), desethylatrazine (DEA), deisopropylatrazine (DIA), desethyldeisopropylatrazine (DEIA), 2hydroxyatrazine (HA), desethyl-2-hydroxyatrazine (DEHA) and ametryn (2) were purchased from Riedel-de Häen, sodium azide $\left(\mathrm{NaN}_{3}\right)$ was purchased from Aldrich, methanol and acetonitrile for HPLC analysis, were purchased from Merck. All other chemicals and solvents were obtained from commercial sources and used as received or distilled and dried by standard procedures. In photolysis reactions, distilled water $(\mathrm{pH} \approx 6.5)$ was used. Millipore (Milli-Q academic system) water was used in HPLC analysis.

The synthesis and characterisation of $5,10,15,20$ tetrakis (phenyl) porphyrin and 5, 10, 15, 20-tetrakis $(2,6$ dichlorophenyl) porphyrin and its sulfophenyl derivatives
TPPS and TDCPPS (Fig. 1) have been described elsewhere (Gonsalves et al. 1996).

Standard solutions $(10 \mu \mathrm{M})$ of pesticides, sensitizers and possible degradation products were prepared by dissolving the required amount of solid in distilled water. For atrazine and ametryn, several days equilibration was necessary to obtain homogenous solutions.

$\mathrm{UV} /$ visible absorption spectra were recorded in quartz cells on a Shimadzu 2100 spectrometer. The $\mathrm{pH}$ control was made using a Crison micro-pH 2000 apparatus. HPLC/UV analysis was performed with an Agilent 1100 series system equipped with a reverse phase C18, Zorbax ODS column $(220 \mathrm{~mm} \times 4.5 \mathrm{~mm}$ i.d., $5 \mu \mathrm{m})$ and a UV-visible detector set at $222 \mathrm{~nm}$. Analysis was carried out with $0.15 \%$ ammonium acetate in water:acetonitrile (50:50 v/v) as an eluent, using a flow rate of $1.4 \mathrm{~mL} / \mathrm{min}$ and an injection volume of $20 \mu \mathrm{L}$.

Experiments with GC-FID were performed with an Agilent $6890 \mathrm{GC}$ system and hydrogen as a carrier gas $(55 \mathrm{~cm} / \mathrm{s})$, using an HP-5 capillary column $(30 \mathrm{~m} \times 0.32 \mathrm{~mm}$ i.d., $0.25 \mu \mathrm{m}$ film thickness). The oven temperature program was as follows: $55^{\circ} \mathrm{C}(1 \mathrm{~min}) ; 35^{\circ} \mathrm{C} / \mathrm{min} ; 250{ }^{\circ} \mathrm{C}(5 \mathrm{~min})$; injector temperature was $250{ }^{\circ} \mathrm{C}$, and detector temperature was $260{ }^{\circ} \mathrm{C}$. The samples were prepared by the extraction of the reaction mixtures with dichloromethane and concentration of the extracts under reduced pressure.

For photolysis experiments, an Applied Photophysics LKS 60 micro reactor was used, with monochromatic wavelength set at ca. $350 \mathrm{~nm}$ from a low pressure mercury lamp.

Transient absorption decays were measured with an Applied Photophysics LKS 60 ns laser flash photolysis kinetic spectrometer, using the third harmonic $(355 \mathrm{~nm})$ of a SpectraPhysics Quanta Ray GCR 130-01 Nd:YAG laser for excitation, a Hamamatsu 1P28 photomultiplier for detection and a Hewlett-Packard Infinium oscilloscope $\left(1 \mathrm{GS} \mathrm{s}^{-1}\right)$. Triplet flash photolysis lifetime measurements were made on aerated and $\operatorname{argon}$ saturated solutions of sensitizer $\left(\sim 2 \times 10^{-5} \mathrm{M}\right)$ in 50:50 acetonitrile:water, with different concentration of pesticides in the range $1 \times 10^{-3}-2 \times 10^{-5} \mathrm{M}$.

\section{Pesticide photodegradation}

Aqueous samples containing the pesticide $\left(4.3 \times 10^{-6} \mathrm{M}\right)$ and sensitizer $\left(4.3 \times 10^{-6} \mathrm{M}\right)$ were prepared. The $\mathrm{pH}$ was controlled and adjusted if necessary with sodium hydroxide or hydrochloric acid, $0.1 \mathrm{M}$ solutions.

Continuous irradiation of the aerated solutions was carried out for 24 and $120 \mathrm{~h}$. The reaction was monitored by both HPLC and UV/visible spectroscopy, to allow the evaluation of the extent of degradation of pesticide and sensitizer, respectively. Degradation products were identified by HPLC-UV by co-injection of available standards. The reaction products were also identified by GC-FID analysis 
Table 1 Photosensitized degradation of atrazine after $24 \mathrm{~h}$ at different $\mathrm{pH}$ values irradiated at $350 \mathrm{~nm}^{\mathrm{a}}$

\begin{tabular}{llll}
\hline Entry & $\mathrm{pH}$ & Sensitizer & Degradation $(\%)$ \\
\hline 1 & 2.1 & - & 63 \\
2 & 7.2 & - & 0 \\
3 & 12.0 & - & 17 \\
4 & 2.1 & TPPS & 59 \\
5 & 5.8 & TPPS & 0 \\
6 & 12.0 & TPPS & 28 \\
7 & 2.1 & TDCPPS & 64 \\
8 & 7.2 & TDCPPS & 5 \\
9 & 12.0 & TDCPPS & 31 \\
\hline
\end{tabular}

${ }^{\mathrm{a}}$ Water solutions of pesticide $\left(4.3 \times 10^{-6} \mathrm{M}\right)$ and (if present) the sensitizer $\left(4.3 \times 10^{-6} \mathrm{M}\right)$.

following the extraction of the reaction mixtures with dichloromethane and concentration on a rotary evaporator.

Photolysis was performed of aqueous solutions of TPPS or TDCPPS, in the above concentrations, in the presence of the singlet oxygen quencher $\left(\mathrm{NaN}_{3}, 4.3 \times 10^{-4}\right)$ to obtain mechanistic insights.

\section{Results and discussion}

Because of the known tendency of charged porphyrins to form aggregates in solution and the consequent influence of this on the photophysical properties, it has previously been shown (Monteiro et al. 2005) that at the concentrations and $\mathrm{pH}$ used for this study, aggregates of TPPS and TDCPPS were not formed.

A series of reactions were performed at different $\mathrm{pH}$ values, both in the absence and presence of TPPS or TDCPPS, to evaluate the $\mathrm{pH}$ effect on atrazine photodegradation. The results were obtained after $24 \mathrm{~h}$ irradiation and are summarized in Table 1.

Atrazine rapidly degrades in the presence of strong acids ( $\mathrm{pH} \mathrm{2,} \mathrm{entries} \mathrm{1,} 4$ and 7). Under these conditions, atrazine degradation appeared only to depend on $\mathrm{pH}$, and not to be affected by the use and type of sensitizer. A more moderate degradation is observed in the presence of strong bases, $(\mathrm{pH}$ 12 , entries 3, 6 and 9). The only reaction product observed by HPLC was 2-hydroxyatrazine (HA), indicating the occurrence of hydrolysis at these extreme $\mathrm{pH}$ values. At near $\mathrm{pH} 7$ (entries 2, 5 and 8) no degradation of atrazine was observed. These results led us to test longer irradiation times for effective photoreactions at this $\mathrm{pH}$ near 7, where there was no hydrolysis of atrazine.

To study the effect of sensitizers TPPS and TDCPPS on the degradation of the pesticide, the reactions were performed in the $\mathrm{pH}$ interval $6-7$, during $120 \mathrm{~h}$ of irradiation. Results are collated in Table 2.

Under these conditions, reaction in the presence of TPPS and TDCPPS led to 30 and $21 \%$ atrazine degradation, respectively. TPPS is completely degraded at the end of the reaction, while only $56 \%$ of TDCPPS degradation was observed, after this irradiation time (Table 2, entries 1 and 2). The different degrees of degradation of TDCPPS under atmospheric pressure or oxygen bubbling (entries 2 and 5) can be related to the extent of the reaction. As indicated in the literature, porphyrins can be photooxidized in the presence of visible light and oxygen to bilinone derivatives (Cavaleiro et al. 1990).

To test for possible participation of singlet oxygen in the photodegradation of atrazine, photolysis was also performed in the presence of $\mathrm{NaN}_{3}$ (entries 3 and 4). This singlet oxygen quencher did not produce any significant effect on atrazine degradation, strongly suggesting that the atrazine degradation mechanism with both sensitizers does not proceed by the type II mechanism involving singlet oxygen.

However, the presence of oxygen seems to be important, as an increase in the degradation was observed when the reaction mixture was bubbled with $\mathrm{O}_{2}$ for 30 min before photolysis (Table 2, entry 5).

To obtain more information about the possible occurrence of a type I mechanism, quenching of the triplet state of sensitizer by the pesticide was studied. Flash photolysis experiments were carried out on deaerated solutions of TDCPPS with $355 \mathrm{~nm}$ excitation, and the decay of the transient absorptions studied at $460 \mathrm{~nm}$, (the T-T absorption maximum of the sensitizer triplet state), in the presence of different concentrations of pesticide.

As low solubility makes it difficult to obtain concentrations of atrazine in pure water above $1 \times 10^{-5} \mathrm{M}$, this study
Table 2 Photosensitized degradation of atrazine in neutral water solution, following $120 \mathrm{~h}$ of irradiation at $350 \mathrm{~nm}^{\mathrm{a}}$

${ }^{\text {aPesticide solutions }}$ $\left(4.3 \times 10^{-6} \mathrm{M}\right)$, sensitizer $\left(4.3 \times 10^{-6} \mathrm{M}\right)$ and (if present) $\mathrm{NaN}_{3}\left(4.3 \times 10^{-4} \mathrm{M}\right)$.

\begin{tabular}{|c|c|c|c|c|c|c|}
\hline Entry & Sensitizer & & $\mathrm{pH}$ & $\begin{array}{l}\text { Atrazine } \\
\text { degradation }(\%)\end{array}$ & $\begin{array}{l}\text { Identified } \\
\text { photoproducts }\end{array}$ & $\begin{array}{l}\text { Porphyrin } \\
\text { degradation (\%) }\end{array}$ \\
\hline 1 & TPPS & - & 7.4 & 30 & DEA, DIA & 100 \\
\hline 2 & TDCPPS & - & 6.5 & 21 & DEA, DIA & 56 \\
\hline 3 & TPPS & $\mathrm{NaN}_{3}$ & 7.5 & 32 & DEA, DIA & 100 \\
\hline 4 & TDCPPS & $\mathrm{NaN}_{3}$ & 6.7 & 19 & DEA & 85 \\
\hline 5 & TDCPPS & $\mathrm{O}_{2}$ & 6.5 & 34 & DEA, DIA & 42 \\
\hline 6 & - & - & 7.2 & 11 & - & - \\
\hline 7 & - & $\mathrm{NaN}_{3}$ & 6.0 & 9 & - & - \\
\hline
\end{tabular}


<smiles>CCNc1nc(Cl)nc(NC(C)C)n1</smiles>

Fig. 2 Photoproducts of atrazine identified by HPLC/UV and GC/FID

was performed in acetronitrile: water (50:50\%) mixtures as solvent, following a control test that photolysis in this solvent led to the same degradation products of atrazine as in pure water.

The decay time of the triplet state in dearated solution is $\approx 250 \mu$ s both alone and with atrazine $\approx 1 \times 10^{-3} \mathrm{M}$ pesticide. This leads to an upper limit for the reaction between sensitizer triplet and atrazine $k_{\mathrm{q}} \leq 4 \mathrm{M}^{-1} \mathrm{~s}^{-1}$. In contrast, the triplet states of the sensitizers are efficiently quenched by oxygen. However, as will be described in a future publication, triplet decay may produce a long-lived intermediate.

From these results, the involvement of singlet oxygen and direct reaction between sensitizer triplet and pesticides seems unlikely. The fact that photodegradation depends on the presence of oxygen suggests that the mechanism may involve formation of superoxide radical anion from reaction between triplet sensitizer and molecular oxygen. However, the concentration of this species should be low as these sensitizers have high quantum yields for singlet oxygen formation (Monteiro et al. 2005) and the reaction via superoxide formation should be a minor pathway, in agreement with the low atrazine degradation. The superoxide radical anion may also lead to hydroxyl radical formation, which can be one of the active species in the photodegradation of atrazine. However, in these reaction conditions $(\mathrm{pH}, \lambda)$, the generation of radical $\mathrm{HO}^{\bullet}$ must occur only in trace amounts, which is confirmed by the absence of hydroxylated products.

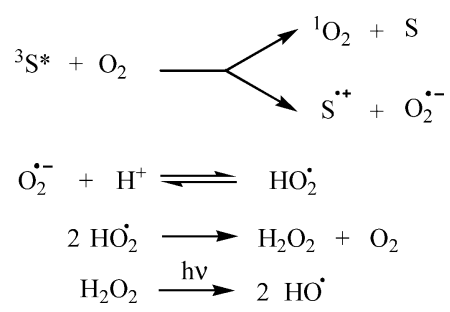

The dealkylated products, DEA and DIA (Fig. 2) were obtained and characterized by HPLC-UV and GC-FID independent of the sensitizer and reaction conditions used. These were identified by comparing their chromatographic behaviour with that of authentic samples.

With the dealkylated compounds, it has recently been shown in studies with bacterial assemblages in natural water, to determine cytotoxicity of atrazine photodegradation products, that DEA and DIA do not have any significant toxic effect on bacterial heterotrophic activity. Instead these photoproducts may be growth substrates for bacterial assemblages in natural water (Zeng et al. 2004).
Table 3 Photosensitized degradation of ametryn in neutral water solution, during $120 \mathrm{~h}$ of irradiation at $350 \mathrm{~nm}^{\mathrm{a}}$

\begin{tabular}{llllll}
\hline Entry & Sensitizer & & pH & $\begin{array}{l}\text { Ametryn } \\
\text { degradation (\%) }\end{array}$ & $\begin{array}{l}\text { Porphyrin } \\
\text { degradation (\%) }\end{array}$ \\
\hline 1 & TPPS & - & 7.4 & 63 & 100 \\
2 & TDCPPS & - & 6.5 & 40 & 42 \\
3 & TPPS & $\mathrm{NaN}_{3}$ & 5.8 & 77 & 100 \\
4 & TDCPPS & $\mathrm{NaN}_{3}$ & 6.7 & 32 & 64 \\
5 & - & - & 6.5 & 4 & - \\
6 & - & $\mathrm{NaN}_{3}$ & 7.0 & 17 & - \\
\hline
\end{tabular}

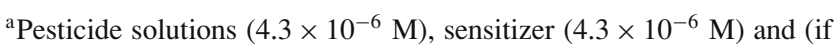
present) $\mathrm{NaN}_{3}\left(4.3 \times 10^{-4} \mathrm{M}\right)$.

The photodegradation of ametryn with TPPS and TDCPPS was carried out under similar irradiation conditions used for atrazine and the results are presented in Table 3. Although suggestions have been given of the importance of C-S homolysis in degradation of this herbicide, our experiments with porphyrin photosensitizer do not allow us to detect this.

The use of TPPS as sensitizer led to more photodegradation than TDCPPS (63\% degradation of ametryn with the first sensitizer compared with $40 \%$ with the second one (entries 1 and 2)).

The degradation of the pesticide in the presence of TPPS and $\mathrm{NaN}_{3}$ appears to lead to a higher conversion than with the sensitizer alone (entry 3). However, this result can be explained, as it was also observed that $\mathrm{NaN}_{3}$ alone leads to $17 \%$ ametryn degradation (entry 5 ). We can thus conclude that singlet oxygen is not important in the photodegradation mechanisms of these two herbicides with TPPS.

However, the reaction of TDCPPS in the presence of this singlet oxygen scavenger may have led to a slight decrease in the percentage of degradation, indicating some possible contribution from a type II mechanism, involving singlet oxygen. As with atrazine, flash photolysis studies show that the decay of the triplet state of the sensitizer is not affected by the presence of ametryn. Again, the photosensitized degradation mechanism most probably involves superoxide radical anion.

\section{Conclusion}

The herbicide atrazine shows $30 \%$ photodegradation with visible light in the presence of the water soluble porphyrins TPPS or TDCPPS as sensitizers, following $120 \mathrm{~h}$ irradiation, while ametryn shows $63 \%$ breakdown. The reaction products are dealkylated derivatives, which in the case of atrazine are suggested to be of low toxicity. Although more detailed mechanistic studies are needed, this study suggests that the mechanism involved in the photodegradation of atrazine using TPPS or TDCPPS probably proceeds via $\mathrm{O}_{2}^{-\bullet}$ and $\mathrm{HO}^{\bullet}$ 
radicals. With ametryn, using TDCPPS there may be some contribution of singlet oxygen.

Acknowledgments Financial support for the collaboration between Clermont-Ferrand and Coimbra by ICCTI/GRICES and CNRS is gratefully acknowledged. We also thank FCT, POCTI and FEDER for further funding. S.L.H. Rebelo also thanks FCT for a post-doc grant.

\section{References}

Azenha MEDG, Burrows HD, Canle ML, Coimbra R, Fernández MI, García MV, Rodrigues AE, Santaballa JA, Steenken S (2003) On the kinetics and energetics of one-electron oxidation of 1,3,5triazines. Chem Commun 112-113

Burrows HD, Canle ML, Santaballa JA, Steenken S (2002) Reaction pathways and mechanisms of photodegradation of pesticides. J Photochem Photobiol B: Biol 67:71-108

Cavaleiro JAS, Neves MGPS, Hewlins MJE, Jackson AH (1990) The photo-oxidation of meso-tetraphenylporphyrins. J Chem Soc Perkin Trans 1:1937-1943

De Rosa MC, Crutchley RJ (2002) Photosensitized singlet oxygen and its applications. Coord Chem Rev 233-234:351-371

Foote CS (1991) Definition of type I and type II photosensitised oxidation. Photochem Photobiol 54:659

Gonsalves AMd'AR, Johnstone RAW, Pereira MM, SantAna AMP, Serra AC, Sobral AJFN, Stocks PA (1996) New procedures for the synthesis and analysis of 5,10,15,20tetrakis(sulfophenyl)porphyrins and derivatives through chlorosulfonation. Heterocycles 43:829-838
Gryglik D, Miller JS, Ledakowicz S (2004) Solar energy utilization in degradation of 2-chlorophenol by immobilized photosensitizers. Solar Energy 77:615-623

Héquet V, Le Cloirec P, Gonzalez C, Meunier B (2000) Photocatalytic degradation of atrazine by porphyrin and phthalocyanine complexes. Chemosphere 41:379-386

Legrini O, Oliveros E, Braun AM (1993) Photochemical processes for water treatment. Chem Rev 93: 671-698

Lichtfouse E, Schwarzbauer J, Robert D (2005) (eds) Pesticides Section. In Environmental chemistry. Green chemistry and pollutants in ecosystems. Springer, Berlin. 69 chapt. pp 461-538

Monteiro CJP, Pereira MM, Azenha ME, Burrows HD, Serpa C, Arnaut LG, Tapia MJ, Sarakha M, Chung P-W-W, Navaratnam S (2005) Photochem Photobiol Sci 4:617-624

Oller et al (2005) Degradation... ECL vol 3, p 118

Rejto M, Saltzman S, Acher AJ, Muszkat L (1983) Identification of sensitised photooxidation products of $s$-triazine herbicides in water. J Agric Food Chem 31:138-142

Silva E, Pereira MM, Burrows HD, Azenha ME, Sarakha M, Bolte M (2004) Photochem Photobiol Sci 3:200-204

Tai C, Jiang G, Liu J, Zhou Q, Liu J (2005) Rapid degradation of bisphenol A using air as the oxidant catalysed by polynuclear phthalocyanine complexes under visible light irradiation. J Photochem Photobiol A Chem 172:275-282

Xiong Z, Xu Y, Zhu L, Zhao J (2005) Photosensitized oxidation of substituted phenols on aluminum phthalocyanine-intercaled organoclay. Environ Sci Technol 39:651-657

Zeng K, Hwang H-M, Zhang Y, Cook S (2004) Assessing cytotoxicity of photosensitised transformation products of 2,4,6-trinitrotoluene (TNT) and atrazine with freshwater microbial assemblages. Environ Toxicol 19:490-496 